Title:

\title{
TIME RESOLVED SIDE SCATTER DIAGNOSTICS AT NOVA
}

Author(s):

George A. Kyrala, P-24

Scott C. Evans, P-24

Johnny R. Jimerson, P-24

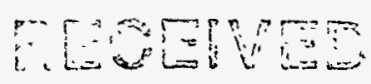

औUd 1 ine

\section{OSTI}

Juan C. Fernandez, P-24

\section{Submitted to:}

11th High Tempature Plasma Diagnostic Conference Monterey, CA

June 13-17, 1996

Also to be published in Review of Scientific Instruments

\section{MASTER}

\section{Los Alamos}

NATIONAL LABORATORY

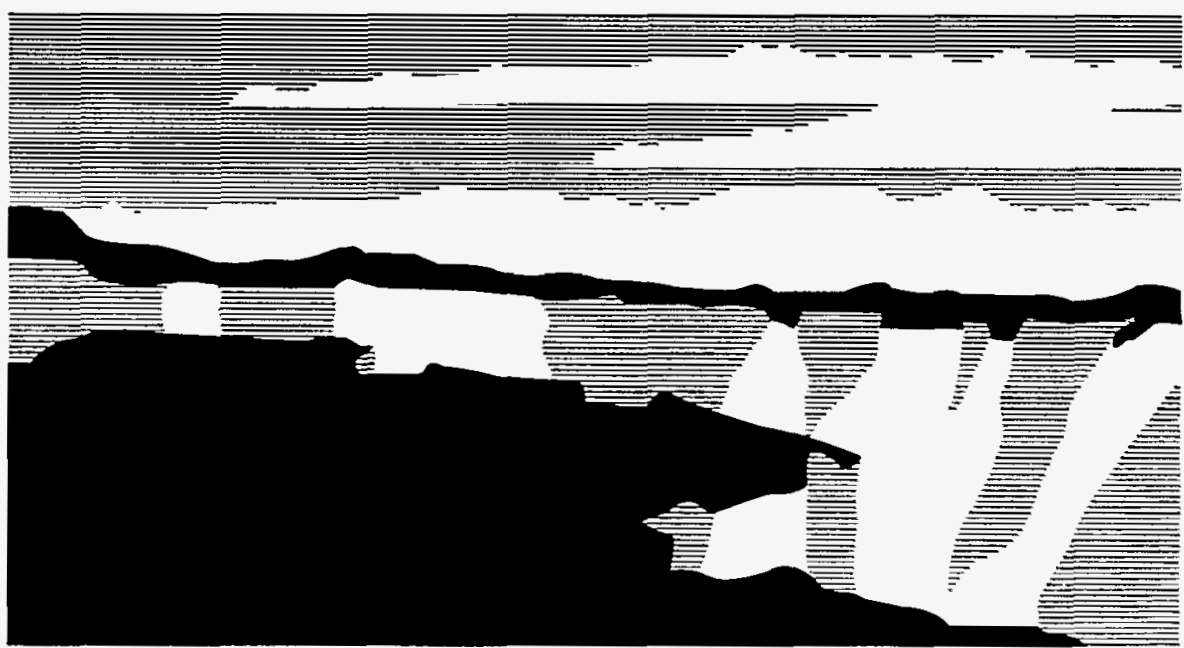

Los Alamos National Laboratory, an affirmative action/equal opportunity employer, is operated by the University of California for the U.S. Department of Energy under contract W-7405-ENG-36. By acceptance of this article, the publisher recognizes that the U.S. Government retains a nonexclusive, royalty-free license to publish or reproduce the published form of this contribution, or to allow others to do so, for U.S. Government purposes. The Los Alamos National Laboratory requests that the publisher identify this article as work performed under the auspices of the U.S. Department of Energy. 


\title{
Time Resolved Side Scatter Diagnostics at NOVA
}

\author{
George A. Kyrala, Scott Evans, Johnny Jimerson, and Juan Fernandez \\ Los Alamos National Laboratory, Los Alamos, NM 87545
}

(Presented 14 May 1996)

Side scattering of the radiation during the interaction of a laser beam with the long scale length plasma in hohlraum is a difficult problem of relevance to the viability of ICF. It is important to measure the absolute amount of the laser side scatter as well as the angular distribution of that scatter. The OSA diagnostics has been implemented on NOVA to measure these quantities. We have implemented a fiber-optically coupled streak camera to measure the temporally and angularly resolved side scatter radiation at $351 \mathrm{~nm}$ at 9 different angles. Filtered PIN diodes were positioned at 31 various angles in the E-field plane and B-field plane of the incident probe beam to sample and measure the scattered radiation at the $351 \mathrm{~nm}$ wavelength of the probe. The diode data was used to calibrate the Brillouin power received by the 9 strategically located fiber optic channels. This presentation will describe the OSA and associated diagnostics.

\section{INTRODUCTION}

Understanding and characterizing laser-plasma interactions, such as absorption, scattering and instability growth are essential to our control and engineering of direct and indirect drive inertial fusion targets. Many instabilities occur during the coupling of the intense laser light into the target plasma. Some of these instabilities compete in scattering the laser light with the resultant loss of useful coupling of the light into the target plasma. Stimulated Brillouin scattering (SBS) is one such process that involves the interaction of a strong laser light with a low-density lowfrequency plasma-density fluctuation. This resonant interaction causes a decay of the laser light into a low frequency ion-acoustic wave in the plasma and a scattered light wave near the incident laser wavelength. It is expected that for low laser irradiances most of the scattering occurs in the backward direction. For other directions of scatter, the most intense scattering occurs in a plane perpendicular to the incident wave vector and the incident Electric field planes. Because the frequency of the ion acoustic wave is much smaller than the incident laser frequency, little of the incident energy is coupled to the plasma. Further, because the instability can occur through out the underdense plasma, a significant fraction of the laser energy can be transferred to the scattered [1]. Competition with other instabilities, or the creation of an overdense plasma using hohlraums, or the increase of the incident laser[2,3]or the interaction with a supersonic plasma [4], all help to reduce the SBS.

At NOVA, during the interaction of multiple beams within a gas filled hohlraum, the hohlraum will be filled by millimeter size underdense $\left(n_{e}>=10^{21} \mathrm{~cm}^{-3}, T_{e}-3-5 \mathrm{keV}\right)$ low Z-plasma which in turn keeps the high- $Z$ wall from filling the hohlraum. This filling allows the laser beams, at least for a while, to reach the High- $Z$ wall where they deposit their energy and laser light is converted to $x$-rays. Although it is expected that most of the SBS is scattered in the backward direction, because of plasma refraction, and the three dimensional geometry of the hohlraum, a fraction of the laser beams is scattered sideways. In this paper we describe the apparatus used to measure side scattering and we present some of the first data on the absolute magnitude of side scatter.

\section{EXPERIMENTAL ARRANGEMENT}

The experimental arrangement is shown in Figure 1. Nine of the NOVA laser beams, called heater beams, simultaneously enter the $1.6 \mathrm{~mm}$ long, $3.2 \mathrm{~mm}$ diameter, cylindrically symmetric gas-filled gold hohlraum through two $1.6 \mathrm{~mm}$ diameter laser entrance holes LEH's located on the axis of the hohlraum. A tenth beam, beam 7 , enters the hohlraum at a separate time from the other beams and acts a sampling beam for the plasma. The laser beams are pointed to $0.1 \mathrm{~mm}$ beyond their LEH's along the axis of the hohlraum. The laser beams are focused $1.4 \mathrm{~mm}$ in-front of the LEH by an F/4.3 lens. The ten heater beams may be shaped in time. Typically they turn on at zero time with $100 \mathrm{ps}$ rise time, then in $1.4 \mathrm{~ns}$ they slowly increase to 1.5 times the initial power. By contrast the interaction beam 7 has a 1-ns square pulse shape that starts at $0.4 \mathrm{~ns}$ after the heater beams, thus allowing interaction with a preformed, preheated, welldeveloped hohlraum plasma. The laser beams are linearly polarized with their E-field direction, their propagation direction and the axis of the hohlraum forming one plane. Three optical systems observe the beam interactions, FABS the full aperture backscatter diagnostic [5], NBI the near backscatter image diagnostic [3], and the OSA oblique scatter array. FABS observes the beam that retroreflects into the focusing optics $\left(180^{\circ}-173^{\circ}\right)$, NBI measure the scatter in the angular range $\left(162^{\circ}-173^{\circ}\right)$ and the OSA samples the scatter from $162^{\circ}-0^{\circ}$, where all the angles are measured from the beam propagation vector, $\mathrm{k}_{0}$, direction. The NBI and FABS systems have been described previously, in what follows we will describe the OSA system. The OSA diagnostic is based on two sets of subsystems; a diode array that measures the absolute scattered energy, and a fiberoptically coupled system that measures the corresponding time history of the power received by the diode array . 


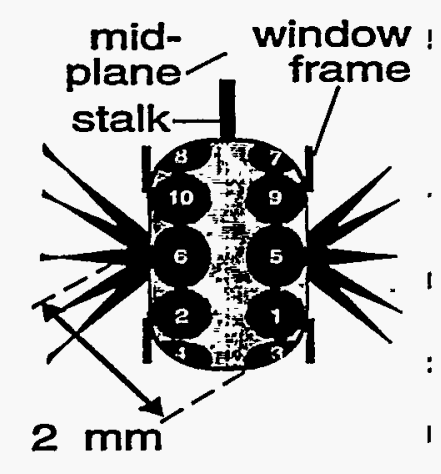

FIG. 1. Schematic of the target.

\section{DIODES}

The total sidescattered energy is measured using an array of 31 filtered PIN diodes, called the oblique scattered array OSA. At each of 31 different angular positions in the E-Field B-field polarization planes of beam \#7, a standard detector package is placed at the wall of the target chamber. Each package consists of a heavily shielded $5 \mathrm{~mm}$ active diameter PIN-diode filter combination with $50 \mathrm{ohm}$ output. The diode is standard PIN diode a planar diffused structure with a $\mathrm{p}+\mathrm{Si}$ cathode [\# 9665-A made by UDT Corp.], but custom for a $50 \mathrm{ohm}$ output impedance. The light from the target was filtered first by a quartz blast shield that protected the rest of the optics from target debris. The remaining light and $\mathrm{x}$-rays were attenuated by first a $10 \mathrm{~mm}$ thick SF-7 leaded glass glass, to cut down on the hard x-rays from the target. A 2 mm thick UG-11 filter with a broad passband at $359 \mathrm{~nm}$ absorbed the $527 \mathrm{~nm}$ light from the doubled laser beam frequency and the SRS signal, as well as acted as an attenuator at the 1 micron fundamental of the laser beams An interference filter with a central transmission at $350 \mathrm{~nm}$ and a bandpass of $10 \mathrm{~nm}$ was also used to further discriminate against non-SBS scattered light. A $2 \mathrm{~mm}$ thick piece of KG-5 was also used to further limit the $1 \mu \mathrm{m}$ scattered light from reaching the detector. These are then all enclosed inside a steel metal casing to keep out the scattered light and limit the scattered $x$-ray flux from getting to the diodes.

The linearity, calibration, as well as the saturation of these diode packages were investigated at the Trident laser in Los Alamos using a $1 \mathrm{~ns}$ pulse at $350 \mathrm{~nm}$. The charge versus laser energy calibration for a detector is shown in figure 2. When looking at the charge, instead of the voltage amplitude these diodes are linear over many orders of magnitude, the voltage pulse being wider at larger at larger laser energies. The filtering was adjusted to limit the charge to $15 \mathrm{nC}$.

\section{STREAK CAMERA SYSTEM}

While the diodes measure the total side scattered signal, they had no temporal resolution. A fiber optically coupled

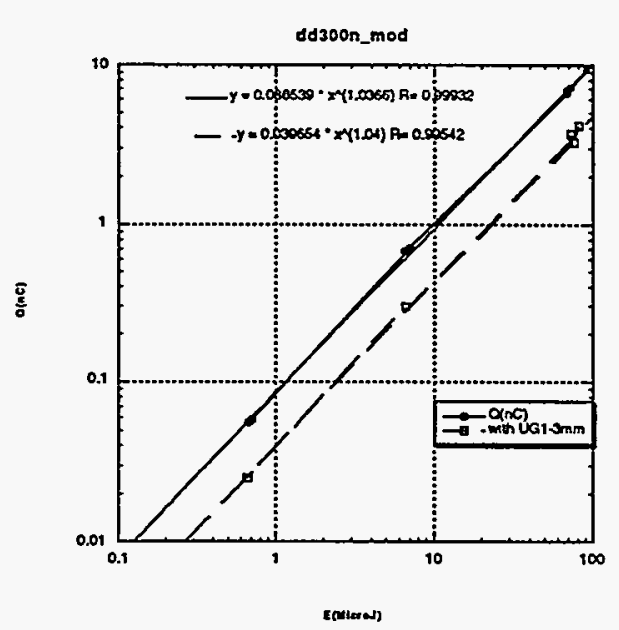

FIG. 2. Linearity of the diodes. The two curves are from two measurements at $351 \mathrm{~nm}$ with a $1 \mathrm{~ns}$ pulse with and without attenuation of a $3 \mathrm{~mm}$ thick UG-11 filter.

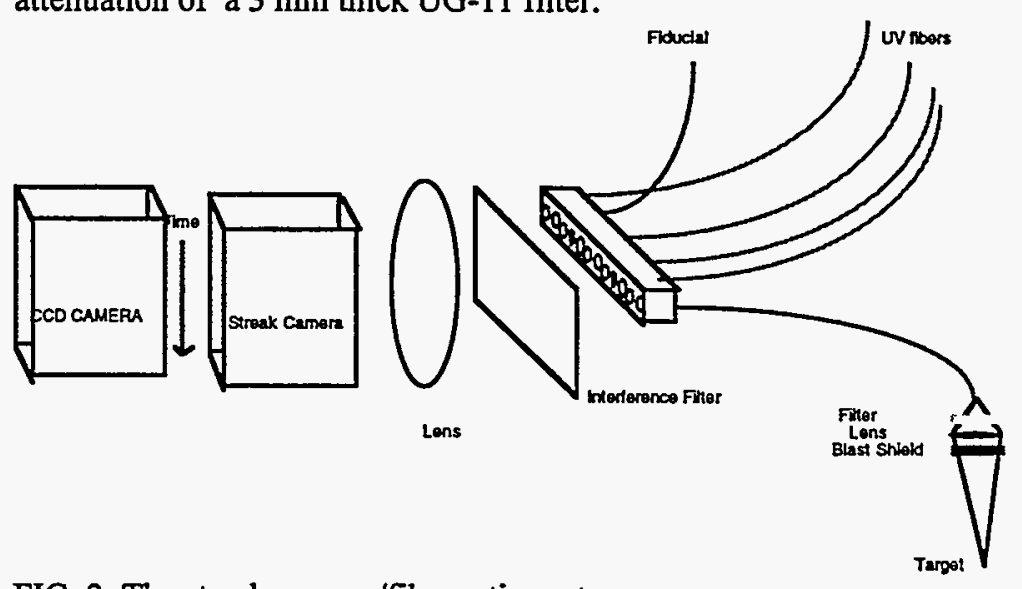

FIG. 3. The streak camera/fiberoptic system.

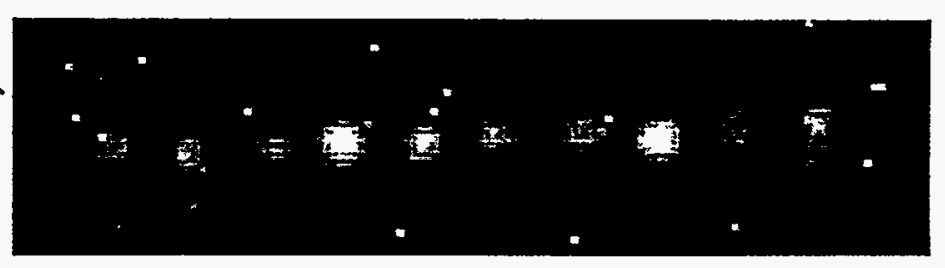

Figure 4. Static Image showing the seperation of the fibers. The distance between the fibers is 11.67 pixels, corresponding to an input separation of $1.27 \mathrm{~mm}$

streak camera system was installed to perform that measurement at few locations around the chamber. Figure 3 shows a diagram of the system. Ten multimode graded-index quartz fibers with a $50 \mu \mathrm{m}$ core-diameter and $125 \mu \mathrm{m}$ cladding-diameter were used to transport the signal to a fast streak camera. The scattered light from the target was collected by a quartz lens of focal length $60 \mathrm{~mm}$ and focused on the input of the fiber. A $1 \mathrm{~mm}$ thick quartz shield protected the lens from target debris. The fibers were made of 


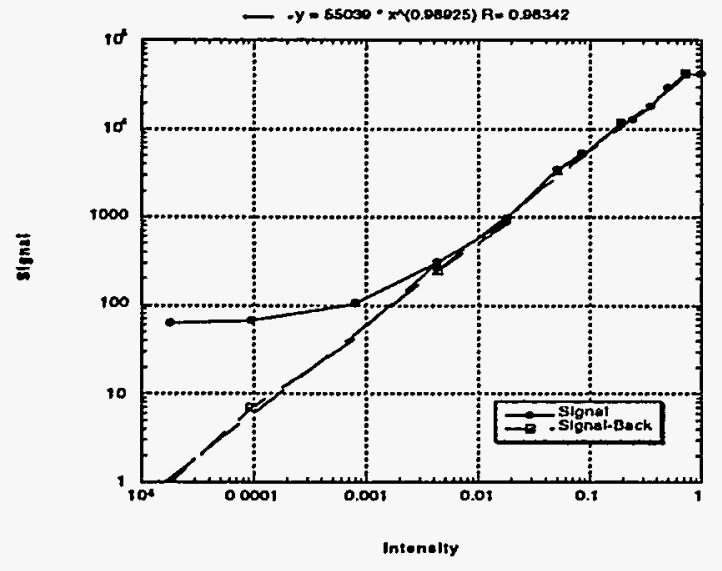

Figure 5. The output linearity of the total system: Streak Camera/intensifier/CCD camera combination. The circles correspond to the signal plus background light, and the squares to the signal. The linearity is within $3 \%$ across the full range of the signal, The saturation is 64,000 counts

different length so that the signals thus allowing for less cross talk among the channels. One of the channels was connected to the NOVA fiducial system, which gave us a 100 ps pulse at $527 \mathrm{~nm}$, with a fixed delay relative to the laser pulse. All the channels were then grouped in an linear array with a fixed spacing of $1.27 \mathrm{~mm}$ arrive at the streak camera at various times. Because the streak camera photocathode was located few $\mathrm{mm}$ behind a $1 \mathrm{~mm}$ thick sapphire input window, an imaging system was used. The $18-\mathrm{mm}$ wide fiber-array was imaged on the 6-mm wide S-20 photocathode of the streak camera. Two $19-\mathrm{mm}$ diameter quartz lenses with an effective focal length of $32.5-\mathrm{mm}$ were used to demagnify the image. A $350 \mathrm{~nm}$ multicavity interference filter with $10 \mathrm{~nm}$ bandpass and an off band rejection of $.01 \% \mathrm{~T}$ was placed at the input of the streak camera between the fiberoptic array and the focusing lens, but avoiding the fiducial channel. Imaging the large area intensifier output ( $40 \mathrm{~mm}$ diameter) onto the $1 \mathrm{~cm} \mathrm{x} 1 \mathrm{~cm}$ CCD camera sensitive area presented a special problem because of the short distance between the streak camera intensifier and the CCD camera. A $50 \mathrm{~mm}$ F/1.2 lens was used with a $36 \mathrm{~mm}$ extension tube and a +4 close-up lens to accomplish the task. Figure 4 shows a static image of the array at the CCD camera. The fibers were well resolved with a separation of 11.67 pixels and a spatial demaginfication of $108 \mathrm{~mm}$ per pixel. The output linearity of the camera was measured. Figure 5 shows the output counts versus the input signal. The output from the camera was digitized by 16 bits digitizer with a fixed pattern readout noise of 2 bits and a dark current of 2 bits per 10 seconds of integration time. The dynamic range extracted from figure 5 is more than 30000 , and is mainly limited by the dynamic range of the intensifier.

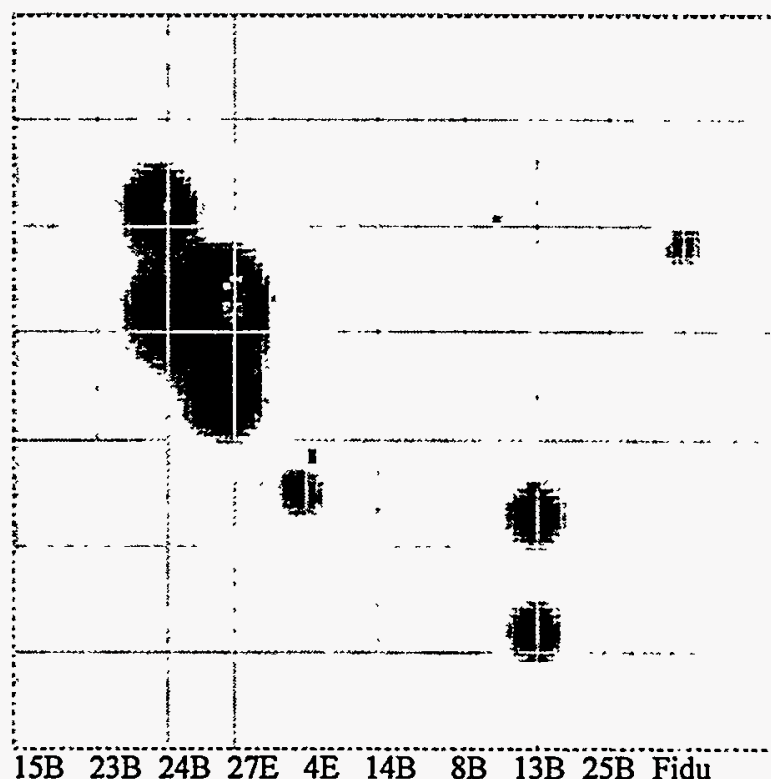

Figure 6. Typical output from the streak camera for a passthru shot 25100419 with a neo-pentane fill. The vertical bars indicate the positions of the fibers, the horizontal lines are spaced $1 \mathrm{~ns}$ apart. The notation for location is $\mathrm{xxA}$ or $\mathrm{xxB}$ where $\mathrm{xx}$ is the angle in tens of degrees, $\mathrm{E}$ is in the $\mathrm{E}$ filed plane, and $B$ in the B-field plane

\section{OBSERVATIONS}

One typical measurement by the fiberoptically coupled streak camera system is shown in Fig. 6. Line outs from the different observation directions are shown in figure 7 . It is seen that there are different temporal components to the measured diode signals. The late time emission occurs when the laser beam penetrates the first window and illuminates the opposite side. The contribution to side scatter from the heater beams occur earlier in time, and can be separated from the probe beam contributions. The angularly resolved total scattered energy, as measured by the diodes is shown in figure 8. If we separate and subtract the heater beam contribution then the side scatter energy is less, but the angular distribution in the measured channels does not change much. The angular distribution shows a large contribution between 60 and 80 degrees with respect to the hohlraum axes. That contribution seems to originate from a diagnostic hole that is been used to observe the $90^{\circ}$ SRS side scatter from within the hohlraum.

\section{SUMMARY}

The OSA diagnostic provides an added tool in understanding the side scatter associated with ICF experiments. In combination with other spectral tools it contreibutes to a better understanding of the of laser targetplasma interactions in indirect drive hohlraums and other targets. 


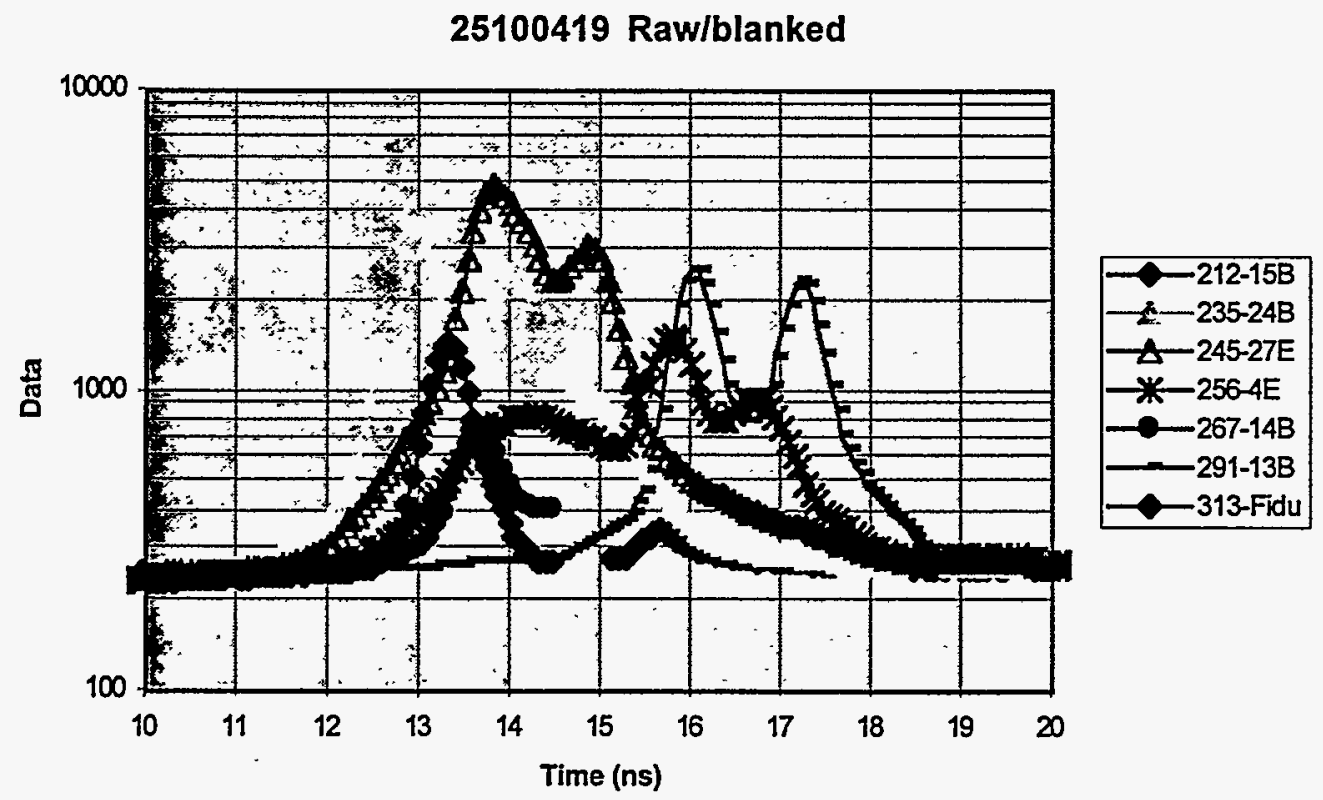

Figure 7. Line outs at the various angular positions.

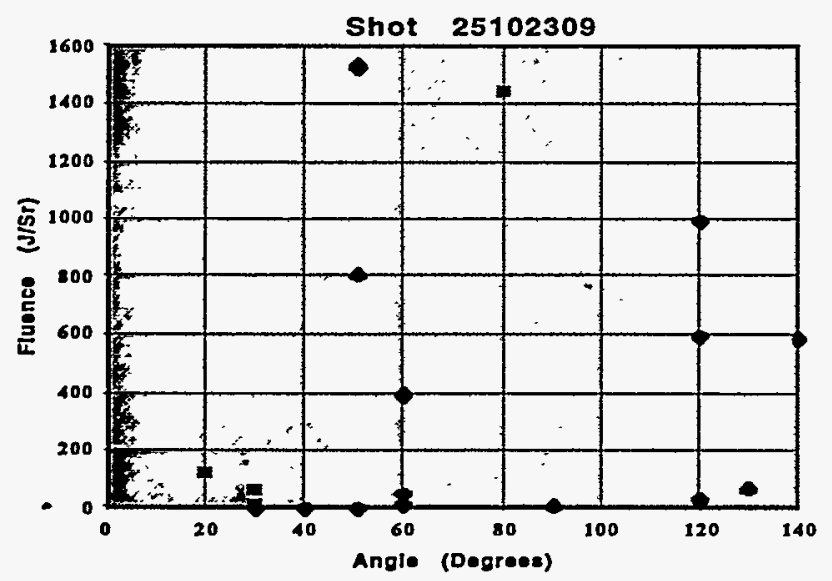

Figure 8. Angular distribution of the scattered light, for inplane $[+]$ and out of plane $[\square]$ scattering.

\section{ACKNOWLEDGMENTS}

The authors would like acknowledge to the Nova operations team and the Los Alamos technicians supporting Nova, specifically Tom Sedillo, Bentley Boggs and Peter Walsh who helped at various stages of the construction. We also acknowledge many discussions with Robert Kirkwood of LLNL regarding the diode efficiency, as well as the help of Randy Johnson of the TRIDENT crew who helped immensly in calibrating the UV diodes on a very tight time scale. This work was supported by the U.S. Department of Energy.

\section{REFERENCES}

[1]-R. A. Haas et al. Phys. Fluids 20, 322 (1977).

[2]-Tanaka et al. Phys. Fluids 27, 2960 (1984

[3]-Fernandez et al, Phys. Rev E53, 2747 (1996).

[4]-T. W. Johnston, G. R. Mitchel, and B. Grek, Phys.

Fluids 25, 179 (1982

[5]-Fernandez J. C. et al Rev. Sci. Instr. 66, 626 (1995), 


\section{DISCLAIMER}

This report was prepared as an account of work sponsored by an agency of the United States Government. Neither the United States Government nor any agency thereof, nor any of their employees, makes any warranty, express or implied, or assumes any legal liability or responsibility for the accuracy, completeness, or usefulness of any information, apparatus, product, or process disclosed, or represents that its use would not infringe privately owned rights. Reference herein to any specific commercial product, process, or service by trade name, trademark, manufacturer, or otherwise does not necessarily constitute or imply its endorsement, recommendation, or favoring by the United States Government or any agency thereof. The views and opinions of authors expressed herein do not necessarily state or reflect those of the United States Government or any agency thereof. 